\title{
Chlorination of phenylallene derivatives with 1-chloro-1,2-benziodoxol-3-one: synthesis of vicinal-dichlorides and chlorodienes
}

\author{
Zhensheng Zhao and Graham K. Murphy*
}

\section{Letter}

\section{Address:}

Department of Chemistry, University of Waterloo, 200 University Ave.

W., Waterloo, N2L3G1, ON, Canada

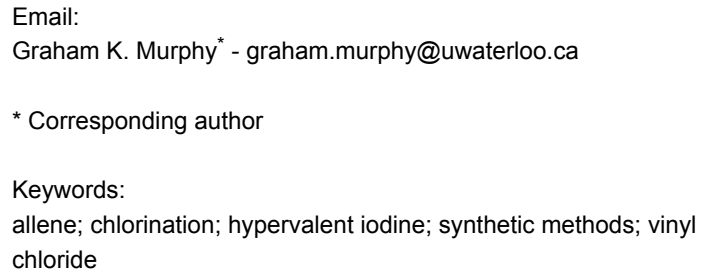

Beilstein J. Org. Chem. 2018, 14, 796-802.

doi:10.3762/bjoc. 14.67

Received: 02 February 2018

Accepted: 22 March 2018

Published: 09 April 2018

This article is part of the Thematic Series "Hypervalent iodine chemistry in organic synthesis".

Guest Editor: T. Wirth

(C) 2018 Zhao and Murphy; licensee Beilstein-Institut.

License and terms: see end of document.

\begin{abstract}
Allyl and vinyl chlorides represent important structural motifs in organic chemistry. Herein is described the chemoselective and regioselective reaction of aryl- and $\alpha$-substituted phenylallenes with the hypervalent iodine (HVI) reagent 1-chloro-1,2-benziodoxol-3-one. The reaction typically results in vicinal dichlorides, except with proton-containing $\alpha$-alkyl substituents, which instead give chlorinated dienes as the major product. Experimental evidence suggests that a radical mechanism is involved.
\end{abstract}

\section{Introduction}

Organochlorine compounds are vital as polymer precursors [1], as pharmaceuticals [2,3] and agrochemicals [4-6] and as functional materials $[7,8]$. And as there is an abundance of chlorinecontaining natural products, the synthesis of chlorinated functional groups, such as allyl- and vinyl chlorides, can represent challenging obstacles that practitioners of natural product synthesis must surmount [9-12]. More commonly, allyl- and vinyl chlorides are highly sought-after intermediates for effecting allylations, and for use in transition metal-catalyzed carbon-carbon and carbon-heteroatom bond-forming reactions [13-28]. Given the versatility of allyl chloride and $\beta$-chlorostyrene groups, installing them in close proximity (as shown in 3 ) provides two handles for rapidly achieving high-density molecular complexity. Thus, the development of strategies for their synthesis is an important endeavour. We envisioned accomplishing this by developing a chemo- and regioselective vicinaldichlorination of phenylallenes; however, no such chlorination reaction has yet been achieved [29-34].

Recent reports of reactions between hypervalent iodine reagents and phenylallenes have highlighted the possible product outcomes achievable through ionic and radical reaction path- 
ways. For example, Liu and co-workers used Togni's benziodoxolone reagent [35] in a radical-mediated vicinal 2,3-difunctionalization of allenes, which proceeded via $\mathrm{CF}_{3}$-radical adduct A (Scheme 1a) [36]. In contrast, Muñiz reported that with $\mathrm{PhI}\left(\mathrm{NTs}_{2}\right)_{2}$, an oxidative amination occurred via cation $\mathbf{B}$, giving regioisomeric propargylamides upon elimination of the iodanyl adduct (Scheme 1b) [37]. Moriarty and Murphy, respectively, showed how reactions of arylallenes with either $\mathrm{PhI}(\mathrm{OH}) \mathrm{OTs}$ [38] or TolIF 2 [39] provide $\alpha$-disubstituted styrenes by sequences involving intermediates analogous to $\mathbf{B}$, followed by a 1,2-phenyl shift (C to D, Scheme 1c). There has been no investigation of the chemistry between arylallenes and chlorinated hypervalent iodine reagents, and given the differing reactivities that might be achievable with (dichloroiodo)benzene [40] (1a) and chlorobenziodoxolone (1b) [30,41-45], there is potential for the selective generation of diverse, poly-chlorinated scaffolds. Reported here are the results of these investigations, and while indiscriminate chlorination of $\mathbf{2}$ was observed with $\mathbf{1 a}, \mathbf{1 b}$ reacted chemo- and regioselectively to give 2,3dichlorides (3) or chlorodienes (4).

\section{Results and Discussion}

We began our investigation of allene chlorination using $p$-tolylallene (2a), prepared from 4-methylstyrene through
Doering-Moore-Skattebøl reaction [46], and iodane 1a. The reaction was carried out using a slight excess of $\mathbf{1 a}$ in acetonitrile, at both room temperature and at reflux, and upon consumption of the allene an inseparable mixture of chlorination products $\mathbf{3 a}$ and 3a' were obtained. While the overall yield of the chlorinated products increased when under reflux conditions, very little change in chemoselectivity was observed (Scheme 2) [31]. As these results were consistent with those achievable by other allene chlorination reactions, it was not investigated further.

We next investigated the chlorination of $\mathbf{2 a}$ with benziodoxolone 1b [47-49], which proved highly regioselective. An initial reaction with 2.2 equiv of $\mathbf{1 b}$ in acetonitrile at room temperature failed; however, repeating the reaction under reflux conditions gave $3 \mathbf{a}$ as a mixture of $E / Z$ alkenes in $58 \%$ yield (Table 1 , entries 1 and 2). The reaction was entirely selective for the terminal alkene, with none of $\mathbf{3 a}$ ' being observed. Toluene, chlorobenzene, DMF and DCE were also tested as reaction solvents, but none were superior to acetonitrile (Table 1, entries 3-6). A small improvement in yield was achieved by adding $\mathbf{2 a}$ dropwise over 30 minutes (Table 1, entry 7), and we ultimately found that adding $\mathbf{2 a}$ dropwise over one hour was optimal, giving 3a in $90 \%$ yield as a $E: Z=1: 1.25$ mixture (Table 1 ,

a) vicinal-functionalizaton of arylallenes: Liu [36]

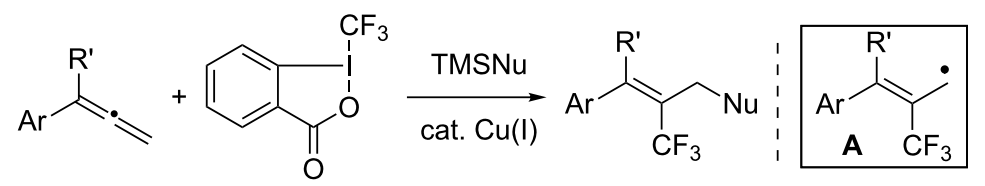

b) oxidative amination of arylallenes: Muñiz [37]

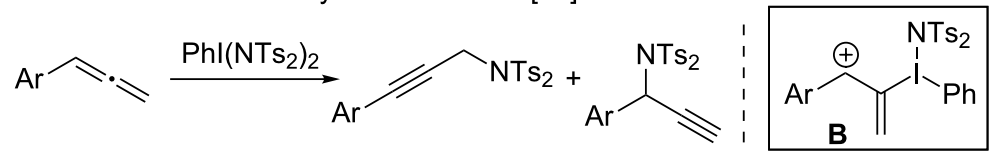

c) oxidative and fluorinative rearrangement of arylallenes:
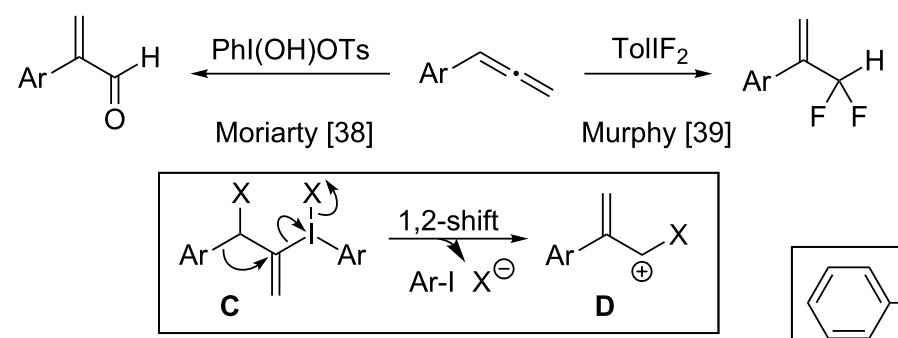

d) this work: chlorination of allenes using HVI reagents:
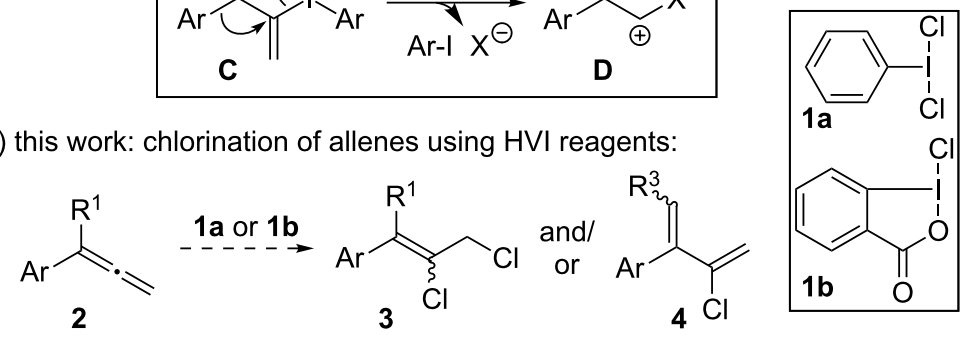


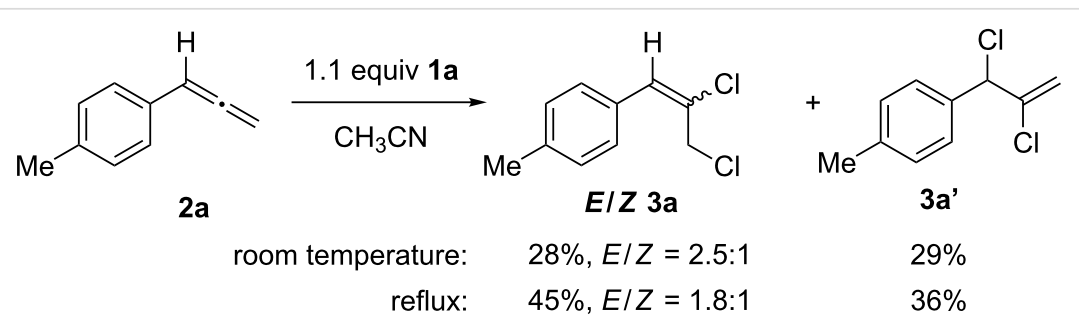

Scheme 2: Chlorination of p-tolylallene (2a) with (dichloroiodo)benzene (1a).

entry 8 ). One final reaction was carried out using the related gem-dimethyl chlorobenziodoxole [49], but the yield of 3a decreased to $45 \%$ (Table 1, entry 9). This result is the first example of a selective chlorination reaction of phenylallenes, and as the regiochemical outcome parallels that observed by Liu (Scheme 1a), it is likely that radical pathways are involved [50].

Table 1: Optimization of the reaction conditions. ${ }^{a}$
solvent, temperature

aGeneral conditions: Allene 2a (0.2 mmol, 1 equiv), $\mathbf{1 b}(0.44 \mathrm{mmol}$, 2.2 equiv) in $0.1 \mathrm{M}$ solvent under reflux conditions for $2 \mathrm{~h}$; isolated yield. ${ }^{\mathrm{b}}{ }^{1} \mathrm{H}$ NMR yield using HMDSO (hexamethyldisiloxane) as interna standard. 'Dropwise addition of $2 \mathbf{a}$ over $30 \mathrm{~min}$. dDropwise addition of 2a over 1 h. e 3,3-Dimethyl-1-chloro-1,2-benziodoxole used instead of $1 \mathrm{~b}$.

A series of aryl- and allenyl-substituted phenylallenes (2b-v) were then examined in the chlorination reaction. First, phenylallenes with various aryl substituents were investigated, and the $p$-tolyl and $p$-biphenyl derivatives gave the 1,2-dichlorides 3a and $\mathbf{3 b}$ in excellent yield, favouring the $Z$-alkene (Scheme 3 ). The 4-bromo and 2-, 3- or 4-chloro derivatives $\mathbf{2 c - f}$ led to $\mathbf{3 c - f}$ in only moderate yield, with the mass balance of chlorinated materials being made up by the regioisomeric vicinaldichloroination products 3c'-f' (compare with 3a', Scheme 2) [30]. The $p$-anisyl derivative $\mathbf{2 g}$ was also viable in the reaction, giving $3 \mathrm{~g}$ in $64 \%$ yield, as were the 1- and 2-naphthylallenes
( $\mathbf{2 h}$ and $\mathbf{2 i}$ ), which gave the desired dichlorides $\mathbf{3 h}$ and $\mathbf{3 i}$ in $93 \%$ and $78 \%$ yield. In each case, preference for forming the $Z$-alkene was observed, with selectivities ranging from 1.2-4.3:1 Z:E. $\alpha$-Substituents on the allenes were equally viable, as 1,1 -diphenylallene gave $3 \mathbf{j}$ in $84 \%$ yield, and the related mono-methyl and mono-chloro derivatives $\mathbf{2 k}$ and $\mathbf{2 l}$ gave dichlorides $\mathbf{3 k}$ and $\mathbf{3 1}$ in $79 \%$ and $56 \%$ yield, respectively, with little preference observed for formation of either the $Z$ or $E$ alkene. Curiously, with 1,1-di(p-anisyl)allene (2m), only a trace of $\mathbf{3} \mathbf{m}$ was observed, and the reaction instead produced iodobenzoate $\mathbf{3 m}$ " in 57\% yield. Presumably, this anomalous result arose due to the increased stability offered to an electrondeficient radical intermediate by the two methoxy groups, permitting a deviation in reaction outcome.

We next subjected $\alpha$-alkyl-substituted phenylallenes $\mathbf{2 n - v}$ to the standard reaction conditions, which resulted in mixtures of exclusively the $Z$-dichloroalkenes $(\boldsymbol{Z}$-3 $)$ and chlorodienes 4 (Scheme 4). When the para-Br and para-Cl phenylallenes bearing $\alpha$-methyl groups $(\mathbf{2 n}, \mathbf{2 0})$ were tested, the chlorodienes $\mathbf{4 n}$ and 40 were obtained in $31 \%$ and $38 \%$ yield, respectively, along with $23 \%$ of $\boldsymbol{Z}$-3n and $34 \%$ of $\boldsymbol{Z}$-3o. With $\alpha$-methyl naphthylallene derivatives $\mathbf{2 p}$ and $\mathbf{2 q}$, chlorodienes $\mathbf{4 p}$ and $\mathbf{4 q}$ were obtained in $58 \%$ and $65 \%$ yield, along with $37 \%$ and $20 \%$ of the 2,3 -dichlorides. Substrates with $\alpha$-ethyl (2r) and $\alpha$-isopropyl (2s) substituents reacted similarly, giving chlorinated products in $63-65 \%$ yield. Lastly, vinylidene $\mathbf{2 t}$ gave chlorodiene $\mathbf{4 t}$ as the sole product in $74 \%$ yield.

As with alkoxy substrate $\mathbf{2} \mathbf{m}$, the $\alpha$-methylated substrates $\mathbf{2 u}$ and $2 \mathbf{v}$ possessing methoxy group(s) on the arene also deviated from the expected reaction course. These reactions failed to fully consume the starting materials $2 \mathbf{u}$ and $2 \mathbf{v}$, even upon prolonged heating, which we discovered to be the result of $\mathbf{1 b}$ being also consumed through over-chlorination. 4-Methoxy derivative $\mathbf{2} \mathbf{u}$ gave trichloride $\mathbf{5 u}$ in $53 \%$ yield, with no trace of the expected dichloride $\mathbf{3} \mathbf{u}$ or chlorodiene $\mathbf{4} \mathbf{u}$ products observable by NMR (Scheme 5). The 3,4-dimethoxy substrate 2v gave trichlorides $5 \mathbf{v}$ and $6 \mathbf{v}$ in a combined $67 \%$ yield, or in $91 \%$ yield based on the loading of $\mathbf{1 b}$ (Scheme 5). These anomalous outcomes were again rationalized as resulting from the stabi- 


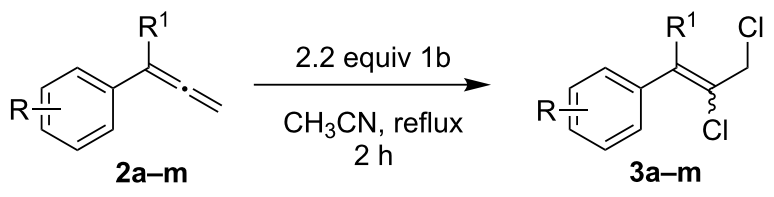

$\mathrm{R}^{1}=\mathrm{H}$ and $\mathrm{Ar}$

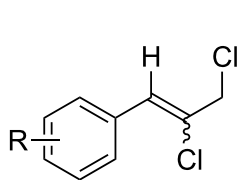

3a, $\mathrm{R}=4-\mathrm{Me}, 90 \%, E / Z=1: 1.25$

3b, $\mathrm{R}=4-\mathrm{Ph}, 88 \%, E / Z=1: 1.4$

3c, $\mathrm{R}=4-\mathrm{Br}, 49 \%, E / Z=1: 2.3$

3d, $\mathrm{R}=4-\mathrm{Cl}, 41 \%, E / Z=1: 1.3$

3e, $\mathrm{R}=3-\mathrm{Cl}, 37 \%, E / Z=1: 1.2^{\mathrm{a}}$

3f, $\mathrm{R}=2-\mathrm{Cl}, 34 \%, E / Z=1: 1.2^{\mathrm{a}}$

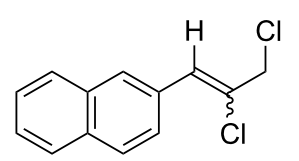

3h $93 \%$

$E / Z=1: 2.6$<smiles>ClC/C(Cl)=C/c1cccc2ccccc12</smiles>

$3 i, 78 \%$

$E / Z=1: 1.9$

$3 g, R=4-O M e, 64 \%, E / Z=1: 4.3$<smiles>ClCC(Cl)=C(c1ccccc1)c1ccccc1</smiles>

$3 \mathbf{j}, 84 \%$<smiles>Cc1ccc(C(=C(Cl)CCl)c2ccccc2)cc1</smiles>

3k, $79 \%$ $E / Z=1: 1.1$<smiles>ClCC(Cl)=C(c1ccccc1)c1ccc(Cl)cc1</smiles>

3I, $56 \%{ }^{\mathrm{b}}$ $E / Z=1: 1$<smiles>COc1ccc(C(=C(Cl)CCl)c2ccc(OC)cc2)cc1</smiles>

$3 \mathrm{~m}$, trace<smiles>COc1ccc(C(=C(Cl)COC(=O)c2ccccc2I)c2ccc(OC)cc2)cc1</smiles>

Scheme 3: Chlorination of various aryl-substituted allenes. General conditions: Allene $2 \mathrm{a}(0.2 \mathrm{mmol}, 1$ equiv) was added dropwise over $1 \mathrm{~h}$ to a solution of $1 \mathbf{b}\left(0.44 \mathrm{mmol}, 2.2\right.$ equiv) in $0.1 \mathrm{M} \mathrm{CH}_{3} \mathrm{CN}$ under reflux conditions, and the reaction stirred for $1 \mathrm{~h}$; isolated yields. ${ }^{a}{ }^{1} \mathrm{H}$ NMR yield using HMDSO as internal standard.

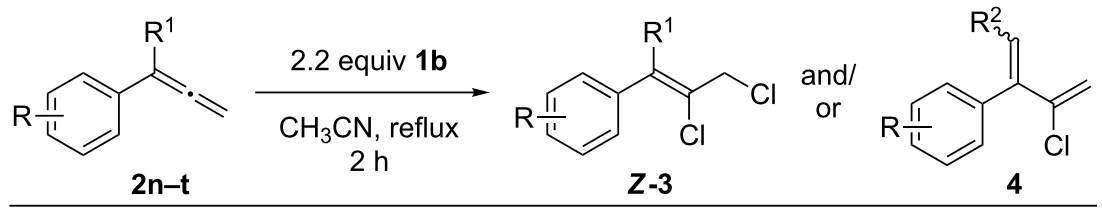<smiles>[R]c1ccc(/C(C)=C(\Cl)CCl)cc1</smiles>

$Z-3 n, R=B r, 23 \%$

$Z-30, R=C l, 34 \%$<smiles>C/C(=C(/Cl)CCl)c1cccc2ccccc12</smiles>

$Z-3 q, 20 \%$<smiles>CC(C)C(=C(Cl)CCl)c1ccccc1</smiles>

Z-3s, $35 \%^{a}$<smiles>[R]c1ccc(C(=C)C(=C)Cl)cc1</smiles>

$4 n, R=B r, 31 \%$

4o, $\mathrm{R}=\mathrm{Cl}, 38 \%$<smiles>C=C(Cl)C(=C)c1cccc2ccccc12</smiles>

4q, $65 \%$<smiles>C=C(Cl)C(=C(C)C)c1ccccc1</smiles>

$4 s, 28 \%^{a}$<smiles>CC(=C(Cl)CCl)c1ccc2ccccc2c1</smiles>

Z-3p, 37\%<smiles>CC/C(=C(/Cl)CCl)c1ccccc1</smiles>

Z-3r, $40 \%^{a}$<smiles>ClC/C(Cl)=C1\CCCc2ccccc21</smiles>

Z-3t, $0 \%$<smiles>C=C(Cl)C(=C)c1ccc2ccccc2c1</smiles>

$4 p, 58 \%$<smiles>C=C(Cl)/C(=C/C)c1ccccc1</smiles>

$4 r, 25 \%^{a}$<smiles>C=C(Cl)C1=CCCc2ccccc21</smiles>

4t, $74 \%$

Scheme 4: Chlorination of various a-substituted phenylallene derivatives. General conditions: Allene 2a ( 0.2 mmol, 1 equiv) was added dropwise ove $1 \mathrm{~h}$ to a solution of $1 \mathrm{~b}(0.44 \mathrm{mmol}, 2.2$ equiv $)$ in $0.1 \mathrm{M} \mathrm{CH}_{3} \mathrm{CN}$ under reflux conditions, and the reaction stirred for $1 \mathrm{~h}$; isolated yields. ${ }^{1} \mathrm{H}_{\mathrm{NMR}}$ yield using HMDSO as internal standard. 
<smiles>C=C(C)c1ccc(OC)cc1</smiles>

2u<smiles>COc1ccc(/C(CCl)=C(\Cl)CCl)cc1</smiles>

$5 u, 53 \%$<smiles>C=C=C(C)c1ccc(OC)c(OC)c1</smiles>

2v<smiles>COc1ccc(/C(CCl)=C(\Cl)CCl)cc1OC</smiles>

$5 v, 30 \%$<smiles>COc1cc(Cl)c(/C(C)=C(\Cl)CCl)cc1OC</smiles>

$6 v, 37 \%$

Scheme 5: Chlorination of methoxy-substituted a-methyl phenylallenes. General conditions: Allene 2a ( 0.2 mmol, 1 equiv) was added dropwise over $1 \mathrm{~h}$ to a solution of $\mathbf{1 b}\left(0.44 \mathrm{mmol}, 2.2\right.$ equiv) in $0.1 \mathrm{M} \mathrm{CH}_{3} \mathrm{CN}$ under reflux conditions, and the reaction stirred overnight; isolated yields.

lization of radical intermediates gained upon methoxy substitution [51], which permitted further chlorination of either the methyl or arene groups.

To gain insight into the reaction mechanism we carried out two key control experiments. First, to test for rearrangement processes that might not be elucidated through product analysis alone, deuterated biphenylallene $\left[\mathbf{D}_{\mathbf{2}}\right]-\mathbf{2 b}$ was subjected to the standard reaction conditions, and $\left[\mathbf{D}_{\mathbf{2}}\right]-\mathbf{3 b}(E / Z=1: 2)$ was obtained in 79\% yield (Scheme 6 top, also see Supporting Information File 1). As there was no indication of deuterium scrambling observable by ${ }^{1} \mathrm{H}$ or ${ }^{2} \mathrm{H}$ NMR of the product mixture, it appeared that 1,2-phenyl shifts or other rearrangement processes were not involved in the reaction. A further reaction was carried out in the presence of the radical scavenger TEMPO ( 1.5 equiv), from which only a trace of $\mathbf{3 b}$ was recovered, along with $50 \%$ of $\mathbf{2 b}$ (Scheme 6 bottom). As the chlorination reactivity was suppressed, our hypothesis that these reactions involved radical intermediates was further supported.

When allene chlorination was carried out with 1a, the observed product distributions were consistent with the results previously obtained, suggesting that ionic processes were operative. Furthermore, since no evidence of propargyl chlorides or $\alpha$-dichloromethylstyrenes were observed, it appears the chlori-

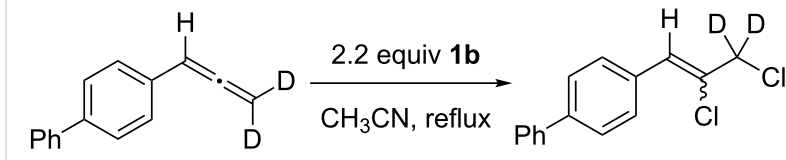

$\left[\mathrm{D}_{2}\right]-2 \mathrm{~b}$

$\left[D_{2}\right]-3 b, 79 \%$

$E / Z=1: 2$

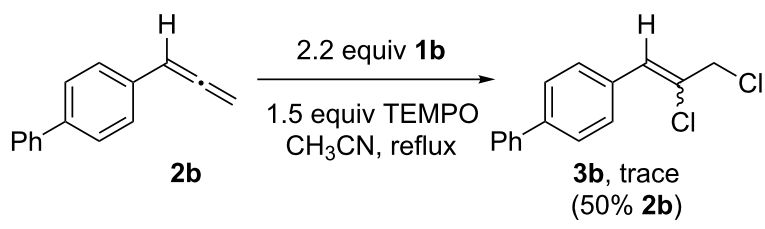

Scheme 6: Control reactions: (a) chlorination of deuterated biphenylallene $\left[D_{2}\right]-2 b$; (b) reaction with TEMPO.

nation of allenes with 1a proceeded without interruption of 1,2phenyl shifts or iodane elimination, resulting in a reactivity pattern that differs from the related reagents $\mathrm{TolIF}_{2}$, $\mathrm{PhI}(\mathrm{OH}) \mathrm{OTs}$ or $\mathrm{PhI}\left(\mathrm{NTs}_{2}\right)_{2}$ (Scheme $1 \mathrm{~b}$ and c). With $\mathbf{1 b}$, however, the reactions were entirely selective for 2,3-dichlorination of the allene, which was consistent with the regiochemical outcome of reactions involving a trifluoromethyl radical (Scheme 1a). This, coupled with the results of Scheme 6, led us to propose a radical mechanism that was initiated by homolytic cleavage of the $\mathrm{I}-\mathrm{Cl}$ bond of $\mathbf{1 b}$ at elevated temperature (Figure 1) [50]. Addition of the chlorine atom to the allene

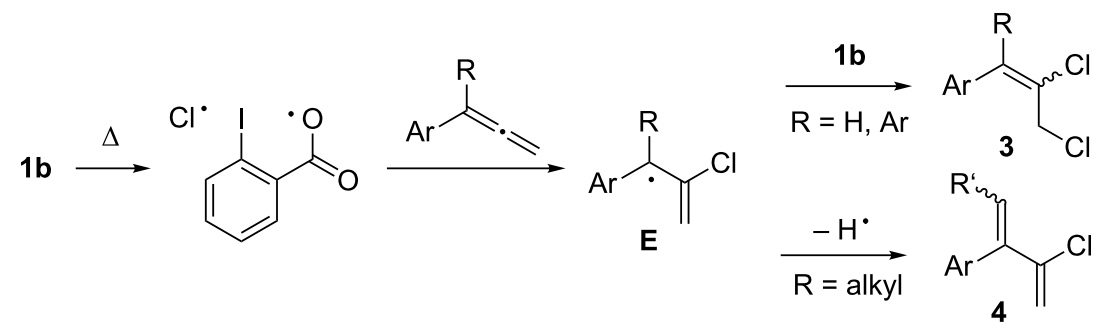


central carbon resulted in the highly stabilized radical intermediate $\mathbf{E}$, which then abstracted a chlorine atom from a second equivalent of $\mathbf{1 b}$, giving dichlorides $\mathbf{3}$. Or, in the case of $\alpha$-alkyl groups, intermediate $\mathbf{E}$ was also subject to a competing hydrogen abstraction pathway, resulting in mixtures of $\mathbf{3}$ and chlorodienes 4 .

\section{Conclusion}

In conclusion, we report here an efficient new process for the chlorination of substituted phenylallene derivatives using the hypervalent iodine reagent 1-chloro-1,2-benziodoxol-3-one (1b). The reactions disclosed here represent the first report of a regioselective chlorination of phenylallenes, in which the 2,3allene olefin undergoes selective vicinal dichlorination. Overall, the reactions were mild and operationally-simple, tolerant to a variety of different functional groups, and provided the products in typically good yield. The selectivity of the reaction is presumably derived from it being a radical, not ionic, process, which also enabled the formation of chlorodiene products with $\alpha$-alkyl substituted allenes. This reaction offers a new strategy for accessing dichlorinated functional group building blocks not readily accessible with other reagents, and our continued work in this area will be disclosed in due course.

\section{Supporting Information}

\section{Supporting Information File 1}

Experimental and characterization details, and NMR spectra of compounds.

[https://www.beilstein-journals.org/bjoc/content/ supplementary/1860-5397-14-67-S1.pdf]

\section{Acknowledgements}

This work was supported by the Natural Sciences and Engineering Research Council (NSERC) of Canada and the University of Waterloo. We also thank Val Goodfellow of the UWaterloo Mass Spectrometry Facility.

\section{ORCID ${ }^{\circledR}$ iDs}

Graham K. Murphy - https://orcid.org/0000-0002-8795-2404

\section{References}

1. Saunders, K. J. Poly(Vinyl Chloride) and Related Polymers. Organic Polymer Chemistry: An Introduction to the Organic Chemistry of Adhesives, Fibres, Paints, Plastics and Rubbers; Springer Netherlands: Dordrecht, 1988; pp 90-112. doi:10.1007/978-94-009-1195-6_4

2. Hernandes, M. Z.; Cavalcanti, S. M. T.; Moreira, D. R. M.; Filgueira de Azevedo Junior, W.; Leite, A. C. L. Curr. Drug Targets 2010, 11, 303-314. doi:10.2174/138945010790711996

3. Smith, B. R.; Eastman, C. M.; Njardarson, J. T. J. Med. Chem. 2014, 57, 9764-9773. doi:10.1021/jm501105n
4. Jeschke, P. Pest Manage. Sci. 2010, 66, 10-27. doi:10.1002/ps.1829

5. Herrera-Rodriguez, L. N.; Khan, F.; Robins, K. T.; Meyer, H. P. Chim. Oggi 2011, 29, 31-33.

6. Jeschke, P. The Unique Role of Halogen Substituents in the Design of Modern Crop Protection Compounds. In Modern Methods in Crop Protection Research; Jeschke, P.; Krämer, W.; Schirmer, U., Eds.; Wiley-VCH Verlag GmbH \& Co. KGaA: Weinheim, Germany, 2012; pp 73-128. doi:10.1002/9783527655908.ch4

7. Tang, M. L.; Bao, Z. Chem. Mater. 2011, 23, 446-455. doi:10.1021/cm102182x

8. Hiszpanski, A. M.; Saathoff, J. D.; Shaw, L.; Wang, H.; Kraya, L.; Lüttich, F.; Brady, M. A.; Chabinyc, M. L.; Kahn, A.; Clancy, P.; Loo, Y.-L. Chem. Mater. 2015, 27, 1892-1900. doi:10.1021/acs.chemmater.5b00329

9. Gribble, G. W. Environ. Sci. Technol. 1994, 28, 310A-319A. doi:10.1021/es00056a712

10. Gribble, G. W. Heterocycles 2012, 84, 157-207. doi:10.3987/REV-11-SR(P)5

11. Wang, B.-G.; Gloer, J. B.; Ji, N.-Y.; Zhao, J.-C. Chem. Rev. 2013, 113, 3632-3685. doi:10.1021/cr9002215

12. Gribble, G. W. Acc. Chem. Res. 1998, 31, 141-152. doi:10.1021/ar9701777

13. Wallner, O. A.; Szabó, K. J. J. Org. Chem. 2003, 68, 2934-2943. doi:10.1021/jo026767m

14. Gosmini, C.; Bégouin, J.-M.; Moncomble, A. Chem. Commun. 2008, 3221-3233. doi:10.1039/b805142a

15. Nakamura, H.; Shim, J.-G.; Yamamoto, Y. J. Am. Chem. Soc. 1997, 119, 8113-8114. doi:10.1021/ja971599e

16. Solin, N.; Narayan, S.; Szabó, K. J. J. Org. Chem. 2001, 66, 1686-1693. doi:10.1021/jo001374d

17. Solin, N.; Narayan, S.; Szabó, K. J. Org. Lett. 2001, 3, 909-912. doi:10.1021/ol015545s

18. Tsuji, J. Pd(0)-Catalyzed Reactions of Allylic Compounds via T-Allylpalladium Complexes. Palladium Reagents and Catalysts; John Wiley and Sons, Ltd.: Chichester, UK, 2005; pp 431-517. doi:10.1002/0470021209.ch4

19. Dounay, A. B.; Overman, L. E. Chem. Rev. 2003, 103, 2945-2964. doi:10.1021/cr020039h

20. Barluenga, J.; Fernández, M. A.; Aznar, F.; Valdés, C. Chem. Commun. 2004, 1400-1401. doi:10.1039/B403655G

21. Reddy, C.; Reddy, V.; Urgaonkar, S.; Verkade, J. G. Org. Lett. 2005, 7, 4427-4430. doi:10.1021/ol051612x

22. Ma, S.; Jiang, X.; Cheng, X.; Hou, H. Adv. Synth. Catal. 2006, 348, 2114-2124. doi:10.1002/adsc.200600234

23. Lemay, A. B.; Vulic, K. S.; Ogilvie, W. W. J. Org. Chem. 2006, 71, 3615-3618. doi:10.1021/jo060144h

24. Geary, L. M.; Hultin, P. G. J. Org. Chem. 2010, 75, 6354-6371. doi:10.1021/jo1014678

25. Rossi, R.; Bellina, F.; Lessi, M. Tetrahedron 2011, 67, 6969-7025. doi:10.1016/j.tet.2011.06.001

26. Thakur, A.; Zhang, K.; Louie, J. Chem. Commun. 2012, 48, 203-205. doi:10.1039/C1CC15990A

27. Han, F.-S. Chem. Soc. Rev. 2013, 42, 5270-5298. doi:10.1039/c3cs35521g

28. Ruiz-Castillo, P.; Buchwald, S. L. Chem. Rev. 2016, 116 , 12564-12649. doi:10.1021/acs.chemrev.6b00512

29. Boyes, A. L.; Wild, M. Tetrahedron Lett. 1998, 39, 6725-6728. doi:10.1016/S0040-4039(98)01410-5

30. Laali, K. K.; Nandi, G. C.; Bunge, S. D. Tetrahedron Lett. 2014, 55, 2401-2405. doi:10.1016/j.tetlet.2014.02.110 
31. Bäckvall, J.-E.; Jonasson, C. Tetrahedron Lett. 1997, 38, 291-294. doi:10.1016/S0040-4039(96)02295-2

32. Mueller, W. H.; Butler, P. E.; Griesbaum, K. J. Org. Chem. 1967, 32, 2651-2654. doi:10.1021/jo01283a073

33. Poutsma, M. L. J. Org. Chem. 1968, 33, 4080-4084. doi:10.1021/jo01275a016

34. Lasne, M. C.; Thuillie, A. Bull. Soc. Chim. Fr. 1974, 249-252.

35. Eisenberger, P.; Gischig, S.; Togni, A. Chem. - Eur. J. 2006, 12, 2579-2586. doi:10.1002/chem.200501052

36. Zhu, N.; Wang, F.; Chen, P.; Ye, J.; Liu, G. Org. Lett. 2015, 17, 3580-3583. doi:10.1021/acs.orglett.5b01677

37. Purkait, N.; Okumura, S.; Souto, J. A.; Muñiz, K. Org. Lett. 2014, 16, 4750-4753. doi:10.1021/ol502179z

38. Moriarty, R. M.; Hopkins, T. E.; Vaid, R. K.; Vaid, B. K.; Levy, S. G. Synthesis 1992, 847-849. doi:10.1055/s-1992-26244

39. Zhao, Z.; Racicot, L.; Murphy, G. K. Angew. Chem., Int. Ed. 2017, 56, 11620-11623. doi:10.1002/anie.201706798

40. Knight, D. W.; Russell, G. A. Phenyliodine(III) Dichloride. e-EROS Encyclopedia of Reagents for Organic Synthesis; John Wiley and Sons, 2001.

41. Xue, C.; Jiang, X.; Fu, C.; Ma, S. Chem. Commun. 2013, 49, 5651-5653. doi:10.1039/c3cc42014k

42. Egami, H.; Yoneda, T.; Uku, M.; Ide, T.; Kawato, Y.; Hamashima, Y. J. Org. Chem. 2016, 81, 4020-4030. doi:10.1021/acs.joc.6b00295

43. Wang, M.; Zhang, Y.; Wang, T.; Wang, C.; Xue, D.; Xiao, J. Org. Lett. 2016, 18, 1976-1979. doi:10.1021/acs.orglett.6b00547

44. Yang, X.; She, Y.; Chong, Y.; Zhai, H.; Zhu, H.; Chen, B.; Huang, G.; Yan, R. Adv. Synth. Catal. 2016, 358, 3130-3134. doi:10.1002/adsc.201600304

45. Parvathaneni, S. P.; Perumgani, P. C. Asian J. Org. Chem. 2018, 7, 324-327. doi:10.1002/ajoc.201700620

46. Wang, Z. Doering-Moore-SkattebøI Reaction. Comprehensive Organic Name Reactions and Reagents; John Wiley and Sons, 2010. doi:10.1002/9780470638859.conrr199

47. Willgerodt, C. J. Prakt. Chem. 1894, 49, 466-482. doi:10.1002/prac.18940490134

48. Keefer, R. M.; Andrews, L. J. J. Am. Chem. Soc. 1959, 81, 2374-2379. doi:10.1021/ja01519a026

49. Amey, R. L.; Martin, J. C. J. Org. Chem. 1979, 44, 1779-1784. doi:10.1021/jo01325a007

50. Li, X.-Q.; Zhang, C. Synthesis 2009, 1163-1169. doi:10.1055/s-0028-1087850

51. Tokumura, K.; Ozaki, T.; Nosaka, H.; Saigusa, Y.; Itoh, M. J. Am. Chem. Soc. 1991, 113, 4974-4980. doi:10.1021/ja00013a037

\section{License and Terms}

This is an Open Access article under the terms of the Creative Commons Attribution License

(http://creativecommons.org/licenses/by/4.0), which permits unrestricted use, distribution, and reproduction in any medium, provided the original work is properly cited.

The license is subject to the Beilstein Journal of Organic Chemistry terms and conditions:

(https://www.beilstein-journals.org/bjoc)

The definitive version of this article is the electronic one which can be found at:

doi:10.3762/bjoc. 14.67 